Digitized by the Internet Archive in 2007 with funding from Microsoft Corporation 
AGRICULTURAL

BUREAU OF AGRICULT YRE LIBRARY,

UNIVERSITY

$\rightarrow$ OF-

CALIFORNIA

FARMERS' BULLETIN NO. 5.

\section{CULTIVATION 0F・TOBACCO}

BY

- Clarence W. DoRsey,

Soll Physicist, in Charge of Soll Investigations.

PREPARED UNDER THE DIRECTION OF THE CHIEF OF THE BUREAU.

MANILA:

BUREAU OF PUBLIC PRINTING. 1903. 


\section{$+2$

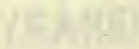

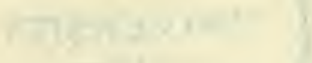

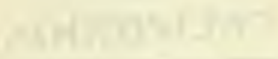




\section{CONTENTS.}

Page.

Letter of transmittal

Introduction

Requirements of the tobacco manufacturer

Preparation of seed bed

Selection of the land

Cultivation of the crop_- 11

Harvesting and curing

Growing tolvacco under shade

Conclusions 19 


\section{LETTER OF TRANSMITTAL.}

Bureau of Agriculture,
Manila, P. I., A pril 22, 1903.

SIR: I have the honor to transmit herewith, for publication as a Farmers' Bulletin of this Bureau, a paper on the cultivation of tobacco. Tobacco occupies a prominent place among the list of exports of the Islands, but the quality of the product is inferior to that formerly grown, and the cultivation of the plant does not receive the attention it should. The cultivation of this profitable crop deserves more widespread attention, for the soil and climatic conditions in many parts of the Philippines are favorable for growing tobacco that can successfully compete with the finest grades produced in the world. To raise tobacco of superior quality, it is necessary that the greatest care and attention should be taken at every stage of growth of the plant, and the present paper is written with the intention of arousing greater interest in the industry and describing some of the more important features of its cultivation.

Respectfully,

Clarence W. Dorsey, Soil Physicist.

Prof. F. Laimson-Scribner,

Chief, Bureau of Agriculture. 


\section{CULTIVATION OF TOBACCO.}

\section{INTRODUCTION.}

In the present paper an effort will be made to describe briefly the methods employed in modern cultivation of tobácco, to treat of recent successes in growing tobacco under shade in the United States, and also describe the conditions of tobacco culture in Sumatra with especial reference to the industry in the Philippines.

In the preparation of this paper the bulletins of the United States Department of Agriculture relating to the cultivation of tobacco have been very freely used and much information has been obtained from the gentlemen connected with the leading tobacco companies in Manila.

Philippine tobacco has long been held in high esteem in the Orient, and Manila cigars maintain the same rank in eastern countries that Havana cigars occupy in Europe and America. To-day tobacco stands third among the exports from the Philippines. During the year 1900 , according to the Monthly Summary of Commerce and Finance of the United States, $11,743,336$ kilos of tobacco, valued at $\$ 1,906,436$, United States currency, were exported from the Islands. Tobacco was introduced into the Philippines shortly after the Spaniards took possession, seed having been brought from Mexico by Spanish missionaries. Little effort was made by the Government to restrict or encourage the cultivation of tobacco until 1781, when the cultivation and sale of tobacco was decreed a State monopoly. While this monopoly was in force, the natives in the large tobacco districts of Luzon were subjected to great inconveniences and even hardships. Each family was compeiled to grow 4,000 plants and deliver the entire crop to the agents of the government. None of the crop could be reserved for the use of the planter, and a fine was imposed when the crop was short. After the crop was harvested the leaves were selected and bought by Government agents, and bundles of inferior leaves were rejected and burned. Native houses were searched for concealed tobacco and fines and penalties imposed on those who did not comply with all the requirements of the monopoly. Early in the nineteenth century many riots and disturbances arose out of the difficulties in meeting the harsh provisions of the law.

In the Visayan and southern Islands the monopoly was not in force, but tobacco raising was not generally practiced until the middle of the 
nineteenth century. The profits from the monoply annually amounted to several million pesos, but was finally abolished on December 31, 1882. Since that time the cultivation and manufacture of the crop has been in the hands of private individuals and companies. At the present time the greater part of the tobacco grown in the Islands comes from Luzon. The products of Isabela and Cagayan Provinces are the most highly esteemed, while considerable quantities are produced in Union and the Ilocos Provinces, on the west coast of northern Luzon. Nueva Ecija formerly raised a fair grade of tobacco, but the cultivation has fallen off in late years. The writer saw in Batangas Province many small fields that would aggregate many hundreds of hectares of tobacco. This is largely used for local consumption, and is of inferior quality. Tobacco is grown in small quantities in the Visayan and southern islands, the greatest amounts probably being produced in Masbate, Tablas, Panay, Bohol, Leyte, Siquijor, Negros, and Mindanao.

Philippine tobacco is nearly all utilized in the manufacture of cigars and cigarettes, and finds a ready sale in Spain (which consumes more than one-half of the total production), England, Hongkong (where it is shipped to Asiatic ports), and British East India. During the year 1900 these countries bought more than seven-tenths of the entire crop. The agreeable aroma and flavor of the better grades of tobacco grown in the Islands have won for it a high place among the fine cigar tobaccos of the world, and, for a long time, it ranked next to the celebrated Cuban tobacco. When we consider the desirable qualities of Philippine tobacco, with the imperfect cultivation, curing, and fermentation it receives, and the improvements and advances that have been made in other tobacco countries, it becomes at once evident that every care and attention should be given the crop to enable it to regain its former position, if not to make it superior to the finest tobaccos grown in the world.

The markets of the United States offer every inducement for the improvement and spread of the Philippine tobacco industry. This becomes all the more evident when we consider the vast sums of money annually expended by the United States for foreign tobacco. During the year ending June 30, 1900, the United States, according to official statistics of the agricultural imports of the United States, paid for Cuban tobacco $\$ 7,615,991$, United States currency, and $\$ 4,569,271$, United States currency, for Sumatra tobacco. During this same year the Philippines exported to the United States only a few hundreds of dollars worth of tobacco, or less than one-hundredth of one per cent of the tobacco importations of that country. While it may be true that Philippine tobacco may never entirely supplant Cuban and Sumatra tobacco in the United States, there is certainly every inducement to encourage and improve the industry until modern cultural methods have realized to the fullest extent the highest perfection of the crop. 


\section{REQUIREMENTS OF THE TOBACCO MANUFACTURER.}

In the manufacture of high-grade cigars certain essentials are necessary. The tobacco must burn smoothly and freely, with a pleasant tastenot rank and strong, nor too mild. When the taste is pleasant, not sharp and bitter, the aroma will invariably be good. The cigar that possesses the above qualities will meet with a ready sale. The wrapper of the cigar, as distinguished from the filler, must be light in color, rich in grain, thin in texture, small in vein and stem, very elastic, and of good burning quality. It should stretch and cover well, have little aroma and appear well on the cigar. The most desirable sizes are 40 and 45 centimeter leaves, for from such leaves the manufacturer can obtain four cigar wrappers from each leaf, with but little waste. After such a suitable wrapper leaf is grown, it must be properly cured, assorted and classified. The manufacturer can never afford to pay a high price for a bale of tobacco, unless he can calculate just how many suitable leaves it will contain. This is one reason why Sumatra tobacco commands such a high value, for so carefully is the grading and assorting done that the manufacture knows how many cigars each package of tobacco will wrap, and that the color will be uniform. Wrapper tobacco should be uniform in size, color, and texture; then the buyer knows what he is getting and is willing to pay a good price.

For cigar fillers the leaves should be somewhat shorter, of medium body, have a rich brown color and burn smoothly and freely. The quality of the filler determines the character of the cigar; hence the filler must possess the desirable aroma that distinguishes a good cigar.

Philippine tobacco has some of the above properties and has earned its reputation, on account of its agreeable aroma, fine veins and notable elasticity. This applies only to the better quality of tobacco grown on the alluvial lands of the Cagayan River in northern Luzon. The tobacco grown in the Visayan Islands is coarser, uneven in color, and of greater strength. From the provinces along the west coast of northern Luzon the tobacco is of heavy body, and that grown near the sea has but little combustibility. Its ragged, broken character also lowers its market value. The tobacco grown in Nueva Ecija was formerly considered fine, but the color was a decided yellow, and the taste somewhat bitter.

\section{PREPARATION OF SEED BED.}

No step in the cultivation of tobacco is more important than proper care in the preparation and sowing of the seed beds. This work can not be neglected without running the risk of a partial or total failure of the crop. To make good seed beds is a laborious task and requires good judgment in the selection of the location, soil and in the preparation of the land. To have plenty of good, strong, healthy plants is the surest foundation for a good crop of tobacco, provided they are from seed true 
to the desired standard. It is very important that in the preparation of the seed bed an abundant supply of seed should be sown, and provisions made for a succession of plants; so that, when the planting season comes, the supply of plants suitable for transplanting will be ample for the purpose, and the supply will be maintained throughout the period in which the planting is to be done.

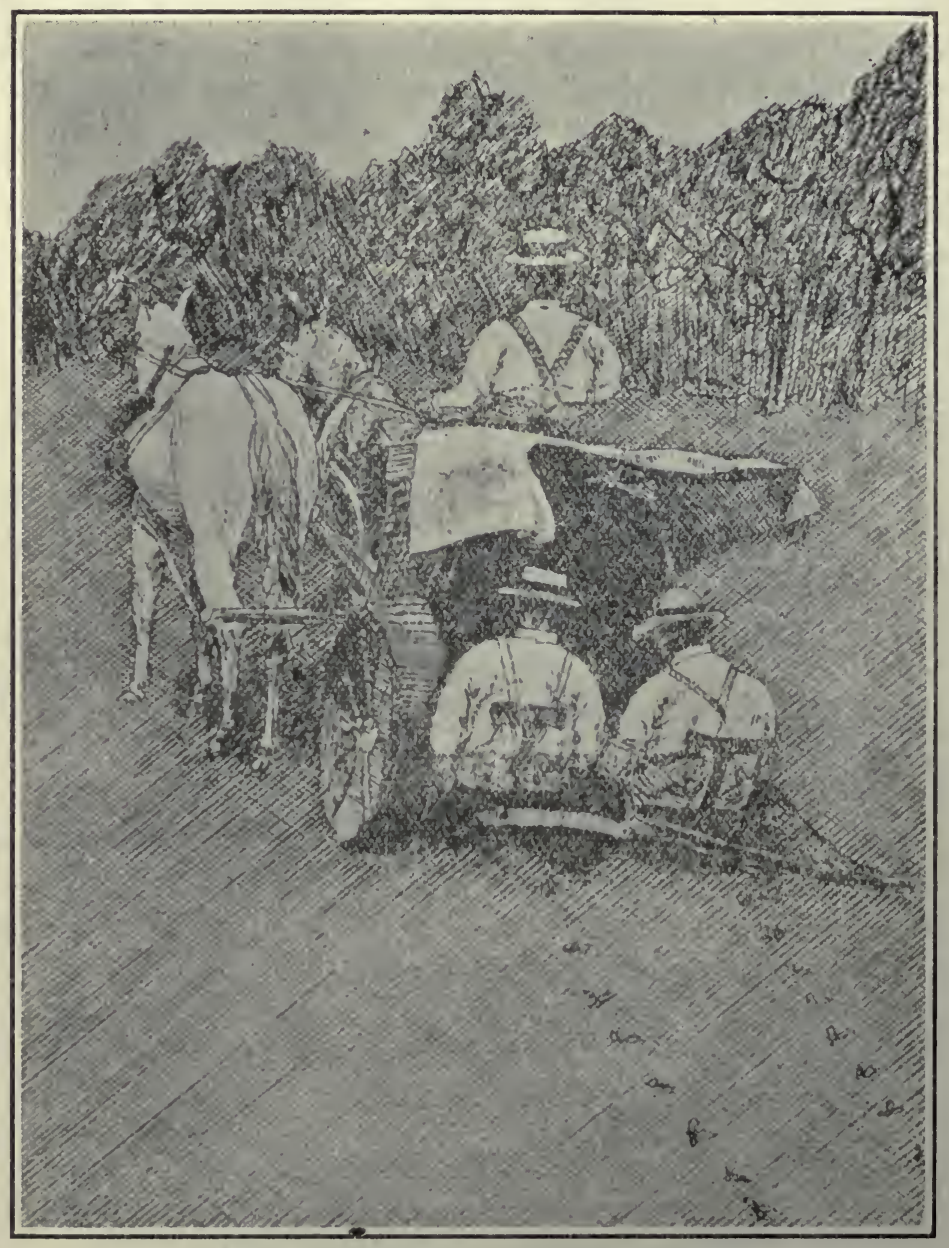

Fig. 1.-Transplanting tobacco plants by machine.

The best soil for the seed bed is a rich, friable, dark, virgin loam or sandy loam. A deep, well-drained soil is greatly to be preferred. The necessary operations of tilling and stirring the soil should precede sowing the seed by several weeks. It is usually customary to thoroughly plow or spade the land and mark the land off into a number of beds surrounded by boards. In the famous Deli district in Sumatra the beds are built up 
ahout 30 centimeters high and surrounded by ditches. The size and number of the beds varies, but they are usually rectangular in size, with suitable walks or passageways between them. The beds are highly fertilized with rich manures or with any complete, specially prepared commercial fertilizer. Stable manure, or any complete guano, may be used. Care should be taken to thoroughly mix the fertilizers with the soil, so that the greatest amount of plant food may be available for the young plants. In the case of old lands, it is. always advisable to burn the land over, to insure safety against grass and weeds. With new land the trouble from such sources is slight; but burning is sometimes practiced, to increase the richness of the soil by adding the fertilizing properties of the burned wood. The burning is usually done one week before planting the seed. After burning, the soil is well spaded and all roots and tufts are carefully removed, and the surface made loose and smooth. Then the soil is well watered and the seed mixed with sand, or sifted wood ashes are nicely spread over the surface. After the seeds are sown the soil should be thoroughly compacted with a heavy roller and, if the soil is at all dry, the beds should be watered and kept continuously moist, but not wet, until the plants are set out. It is best to plant new seed beds at intervals of every few days, in order to be sure to always have fresh plants of proper size on hand when the time comes for transplanting. On a commercial scale it requires about 45 grams of seed to sow a bed 1 hectare in size. In the Cagayan Valley the seed is sown in the beds during the latter part of September and the first weeks of October, while the transplanting is made during the early part of December. This period of planting the seed bed varies slightly in the different parts of the A rchipelago, on account of the varied climatic conditions; but practically all of the transplanting is done during the month of December, as experience has shown this to be the best month for such operations. In many parts of the Philippines it will be found advisable to construct some sort of cover for the seed bed, to protect the seeds and tender plants trom the intense heat of the sun. A suitable shelter made of straw, cogon grass, or nipa palm, raised about 1 meter above the ground, will suffice. It should be so arranged that the covering can be put close together or spread out to regulate the amount of heat received by the small plants. After a few weeks this covering can be removed altogether and kept to serve for another bed. White ants and sometimes caterpillars and worms are destructive in the seed beds, and should be removed by hand or by mixtures of poisonous substances and water, known to be effective in removing such pests. When the plants are drawn for transplanting, great care should be taken to secure as much root as possible. It is usually considered the best practiec to carefully wash away all particles of the seed bed soil that cling to the roots, for the plants live and grow better when the roots are perfectly clean. 


\section{SELECTION OF THE LAND.}

Few, if any, plants are so easily modified as tobacco by climate, soil, elevation, nearness to the sea, and different methods of cultivation. This is plainly demonstrated by the rapid changes which take place in the character of the leaf, flavor, aroma, and special fitness for the varied uses and for different markets in introducing seed of well marked varieties into new districts. Each new class of soil, materially aided by climatic conditons, gives peculiar qualities to the cured leaf as to its flavor, texture, color, etc.

It has long been recognized that tobacco grown near the sea or large bodies of salt water has poor combustibility and, while the taste may be sweet, it commands a low price for the manufacture of cigars on account of its poor burning qualities.

In tropical countries the favored locations for tobacco cultivation are the interior alluvial valleys. In such places the soils are usually deep, porous, easily stirred, and cultivated, and the periodic overflow of the rivers adds new fertilizing elements to the soil, already rich in plant food. The famous tobacco districts of Isabela Province belong to this class, as well as the valley lands of the provinces of the west coast of Luzon. In the Cagayan Valley the quantity of rainfall, according to two years' observation ending in $189 \%$, is much less than at other points in the interior of Luzon, or in tie southern islands. The total amount of rainfall during the year is $700 \mathrm{~mm}$., the greater part of which falls during the period from June to October. During the months of January, February, and March, when the tobacco is growing and ripening, the rainfall does not exceed $20 \mathrm{~mm}$. Comparing the climate of this region with the Deli district in Sumatra, it will be found that the climatic conditions of the latter region more closely resemble those of southern Luzon and some of the southern islands. The rainfall is distributed over the entire year, while the greatest amounts are recorded in October, November, and December. The total amount received during the year averages more than $2,000 \mathrm{~mm}$. The stations in the Philippines, where equivalent or greater amounts of rainfall are recorded, are Bolinao in Zambales Province, Albay in southern Luzon, La Carlota in western Negros, northeastern Mindanao, and Vigan in Ilocos Sur Province.

In Sumatra, where the best results with tobacco have been obtained, the soils are mainly volcanic in origin. Where the finest and silkiest tobacco of a rich brown color is grown, the soils are clayey, while the lighter colors of fine cigar wrapper tobacco are grown on loamy and sandy soils, with clay subsoils. In the clayey soils of the Deli and Langkat districts tobacco can often stand droughts of three weeks and longer, without much injury; but in these districts the frequent light showers are of great value to the growing crop. Experience has also 
shown in Sumatra that the best results have been obtained on land situated from 8 to 16 kilometers from the ocean, while tobacco plantations high up on the mountains have had poor success in growing fine, silky wrapper tobacco. The lowlands, free from frequent inundations and not too near the sea, with soils consisting largely of fine sand and silt, and rich in organic matter, have given the best results.

In the Philippines many fine bodies of interior valley land, with rich, loamy soils, can be found where tobacco cultivation has not been practiced, and it is on such tracts of land that its introduction is especially recommended. Mindanao possesses many large valleys with alluvial soils that could undoubtedly be made to produce a fine quality ot tobacco. The soils of the large valley between Manila and the Lingayan Gulf should be carefully tested with seed from the famous tobacco districts of the world, to determine its fitness for growing tobacco. New areas are constantly being tried in various parts of the world, where tobacco growing was unknown, and the success of so many of these should prove an incentive to greater efforts on the part of the Philippine planter, to enter into competition to furnish a goodly portion of the world's supply of this profitable crop. Only very recently the cultivation of Havana tobacco has been introduced into Annam and Tokin in French Indo-China, and a portion of the crop exported to Manila. Such an example shows what may be accomplished by careful experimentation in the field of new crops, and should stimulate the energies of farmers in every part of the Archipelago.

\section{CULTIVATION OF THE CROP.}

Since the profits of growing tobacco depend largely on the planter's ability to produce a leaf of such qualities as to make it desirable to the manufacturer, it follows that the greatest care should be exercised in the cultivation of the plant. Prior to the work of transplanting, the ground should be thoroughly plowed or spaded to a considerable depth. Deep cultivation is advisable on any character of soils, as it readily allows the free percolation of rain and air through the soil, and increases the amount of available plant food contained in the soil, and helps to conserve the moisture, especially in times of drought. If only small amounts of manures are to be applied, it can be spread broadcast after the first plowing; but, if large quantities of stable or straw manures are used, it is best to plow them in several weeks before the time of setting out the plants. After plowing, the land should be harrowed with a disk harrow, and then with a smoothing harrow. In Sumatra, where all of the operations are performed by Chinese coolies, the work of breaking the soil is performed by an implement called the "tyankol," a sort of spade, which takes the place of the plow, while the work of smoothing and reducing the soil to a fine state of tilth is accomplished by hoes and iron rakes. Either 
by plows and harrows or by spades and rakes, the field should be made loose and smooth before transplanting, or the young plants are at a disadvantage from the very start. The writer has, seen many fields, especially in Batangas Province, where young tobacco plants were attempting to grow in a field filled with the hard clods of intractable clay soil. Such methods are to be condemned, for plants as tender and delicate as tobacco can not make a good growth in improperly prepared fields.

Often it will be found advisable to water the field before the work of transplanting begins. Transplanting can be done by hand or by a transplanting machine. Such a machine can only be used on level fields free from stumps, stones or large quantities of undecomposed vegetable matter. By its use more satisfactory results are obtained, and large

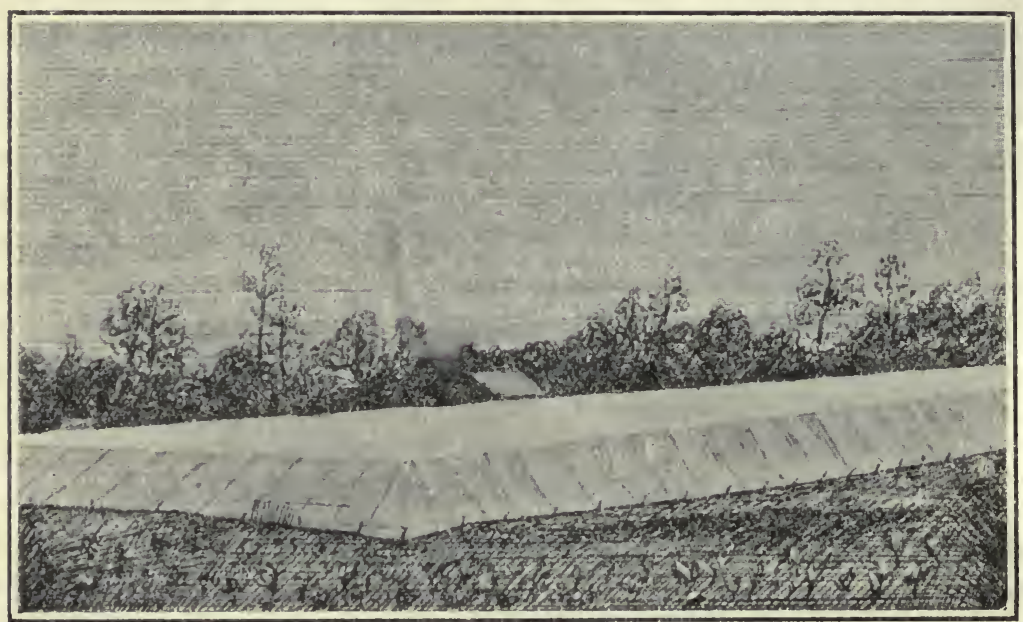

FIG. 2.-A tobacco field covered with a cheese-cloth shelter.

areas can be planted at much less expense than by hand-planting. A transplanter is a two-wheeled machine drawn by two horses or mules. One man drives, while two boys drop the plants. Plants are set with mathematical regularity, at any distance desired. The machine is so arranged that a supply of water is furnished at the time of planting, so that the plants are thoroughly watered while being placed in the soil. Machines of this character are widely used in the United States for setting out tobacco, cabbage, and tomato plants, with exceptionally good results. Machine-set plants start quicker and grow and mature more evenly than hand-set plants. In figure 1 is shown the method of transplanting tobacco plants by machine.

In Sumatra, where all necessary operations are carried on by hand, the coolie is provided with a plant string, the same length as the field. Each 
end of the string is securely attached to a stick of the same length that it is intended the rows shall be separated. This string is divided into intervals by means of colored string, to show the proper distance of the plants in the row. By means of a sharp stick, holes are made at the proper distance, about 10 centimeters deep and 7 centimeters in width. The holes are watered immediately before the plants are put in. The plants are pulled from the bed when the dew is still on them, and set out late in the afternoon, when the rays of the sun are not very strong. T)uring the daytime the pulled plants are kept in a basket and carefully watered, and covered with cloth. About 4 o'clock in the afternoon, the coolie drops from the basket a plant beside each hole and, when all of the plants are dropped, commences to plant. He holds the plant in the center of the hole with his left hand and, with his right hand, presses the soil around the roots carefully but firmly, so that he can give the plant a slight pull without removing it.

As regards the number of plants to the hectare, this depends so largely on experience and the character of the soil and the kind of tobacco that special directions can not be given. Close planting in the row tends to develop a very thin leaf, while open planting allows the leaves to grow to a greater size, and develops the gums and oils so common to tobacco. For cigar wrappers it is usual to plant closely in the row, in.order that the leaves will shade each other and develop the fine, thin leaves desired for this purpose. In Sumatra as many as 10,000 plants are set out in a field of $1 \frac{1}{3}$ acres (slightly more than one-half of a hectare). For cigar fillers or for tobacco to be used for manufacturing purposes, the planting is much more widely separated than in Sumatra.

As it is always desirable to get a uniform growth, great care should be exercised to have each plant live. Replanting should be done as quickly as it is possible to determine where fresh plants are needed. If the soil is moist and showers are frequent, watering the plants is unnecessary; but, if the ground is dry, they should be watered immediately after setting and each day thereafter, as long as the plants require it. 'T'he quantity of water used is in all cases governed by the condition and nature of the soil. Usually, after setting, the plants are undisturbed for a period of several days, during which time they are taking root. After this time cultivation should be begun and continued rapidly and frequently, until further cultivation is liable to injure the growing leaves. Cultivation at first can be done by a light plow or hoe; but, after the plants have reached a considerable height, only the hoe should be used, and this very lightly. At this period the leaves furnish sufficient shade to prevent the soil from baking and hindering the growth of the surface roots.

Every effort is made, both through fertilizing and cultivation, to main- 
tain a steady and rapid growth, as any check in the rate of growth tends to thicken the leaf and reduce its elasticity. Stable manures are commonly used, while fertilizers known to be rich in potash are especially to be recommended. In many parts of the United States it is customary to apply specially prepared fertilizers after the plants have attained considerable size, to still further stimulate the growth of the crop. In Sumatra the crop is given three cultivations. The second cultivation is made at the time the plants are about 30 centimeters high. Just before the second cultivation, the coolie carefully removes the lower leaves, places them around the stem, and packs the loose soil on these. At this second cultivation the suckers are broken off and buried in the same way as the leaves, so as to protect the stem. The work of topping and suckering varies considerably, with reference to individual plants and the character of tobacco desired.

Early or low topping is not desirable, as it throws too much growth into the leaves, making them coarse and large. If the plants are thrifty and the weather favorable for growth, it is frequently advisable, if thin, fine-textured leaves are desired, not to top the plants at all, but let them produce their flowers and seed pods. If, however, the plants seem weak and it appears that they can not mature the full number of leaves, they should be topped by pinch.ng out the "buttons," allowing to remain as many leaves as the plant will be able to mature. When plants have been topped too low and the leaves thicken and curl, a few suckers may be permitted to grow, which will remedy any thickening and curling. By using good judgment in the matter of topping and suckering, and making proper allowance as to the soil and climatic conditions, the leaves can be grown to almost any thickness that is desired.

From the time the plants begin to grow in the seed bed, until they are harvested, they should be examined carefully for worms, insect pests of all kinds, and all of the diseases which they are subject to. Worms may be removed by hand or by applications of mixtures containing poisonous substances, such as paris green. For diseased plants frequently there is $\mathrm{n} n$ other remedy than to remove the plant and reset other plants. But, if the resetting is done too late, the small plants never amount to much.

At the time of topping, or when the buds have made their appearance, a few plants are usually left for seed. Only the best, finest, and healthiest looking plants are selected for this purpose. These are allowed to grow and blossom at their full height. Sometimes all of the leaves are removed; but, usually, only the bottom leaves are taken off. When ripe, the little balls containing the seed are carefully cut off with a knife or other sharp instrument. The cutting must be done carefully, so that the seed will not fall out. The seed pods are then spread out in the sun and, when thoroughly dried, the seeds can be removed. The seed should be cleaned, preferably in a small seed mill, and only the heaviest seed preserved for the next planting. 


\section{HARVESTING AND CURING.}

More satisfactory results are obtained when the leaves are "primed" than when the entire stalk is cut. By cutting the entire stalk, much green tobacco is carried to the shed, since all the leaves never ripen on the plant at the same time. By the system of priming the leaves are taken off the stalk as soon as they ripen, and carried to the drying sheds in baskets. Sometimes half of the leaves are removed and the balance of the stalk cut, and the leaves cured on the stalk. Tobacco should never be cul or primed when wet with rain or dew, as this causes the leaves to sunburn and little holes to form, which lowers the value of the leaf. If the tobacco gives promise of being "wrapper"-that is, if it is light green, very sound in leaf, and of desirable size-it should be primed at an early stage of ripening. If, however, appearances indicate that it will prove "filler" tobacco, it should be allowed to thoroughly ripen.

In the Cagayan Valley it is customary to make five gatherings of the ripened leaves at intervals of eight days. The native cuts the leaves while they are hot and drooping, collects them on his left arm until the bundle is too large, when it is placed on carts and hauled to the sheds.

'The different primings should be kept separate in the shed, so that they can be fermented separately, as each set of leaves from different parts of the plant requires different treatment in the subsequent fermentation.

If the soil is rich and the season favorable, a second profitable crop can be produced from the suckers. 'The first suckers, of course, should be broken off from time to time; otherwise, they will sap, hinder, and check the growth of the leaves. When all of the leaves have been primed from the original stalk except four or six leaves at the top, two suckers should be allowed to grow from the bottom of the stalk. These will be well started by the time the top leaves of the original stalk are ripe. The stalk should then be cut just above where the suckers sprout, and cultivation should begin at once, by carefully placing soil up around the old stubble. The suckers should not be allowed to have more than six or seven leaves each. The growth of these will be rapid, and they will mature early. Usually these are not primed, but the stalks should be cut. In northern Luzon these mature in about three weeks and, in years of great humidity, a second crop of suckers is allowed to grow.

After harvesting, the tobacco is carried to the sheds for drying and curing. These sheds are usually large enough to hold the crop from a number of small fields. Many different kinds of drying sheds are used and differences of opinion prevail as to the relative merits of each style of shed. Some are broad and flat, others narrow and tall. The broad, flat type of barn is to be preferred, for the tobacco cures more slowly, and better results are obtained. The interior of the shed is so constructed that frequent tiers of rafters and posts allow ample support for hanging 
the tobacco. The doors and windows should be arranged with the idea of giving very thorough ventilation when open. The manipulation of the barn or curing shed is entirely governed by the condition of the weather and the nature of the tobacco, and no fixed rules can be given. Considerable care and judgment must be exercised in the curing of the crop, and as the conditions vary in each case from year to year, only experience can determine just what is to be done to meet the new problem in the curing shed. The process requires a few weeks, especially if the leaves have been primed. The crop is considered thoroughly cured when the midribs of the leaves are cured; it is then ready to be taken to the packing house for sorting, fermenting, and baling.

Very much of the value of tobacco depends upon the infinite care that is taken throughout the whole period of its production, and thorough consideration of all the details should be shown in the fermentation,

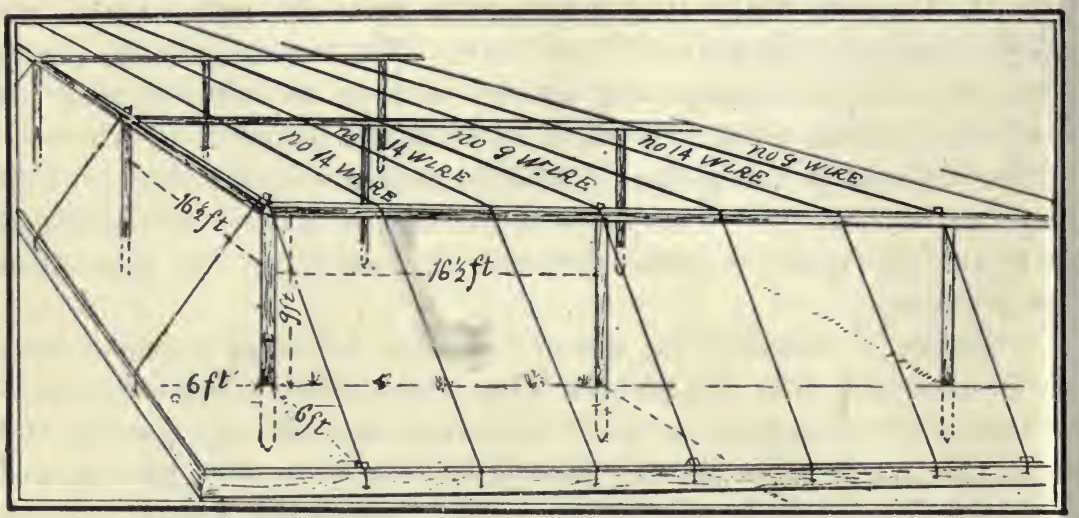

Fig. 3.-Framework for the cheese-cloth covering.

grading, and sorting. The fermentation has two purposes. The first is to insure the proper texture, glossy appearance, and color to the leaf. It brings out the characteristic properties of the leaf, which are hardly apparent when the leaf is cut in the field. It is, furthermore, necessary to press the tobacco into bales, so that it can be shipped in compact form. The best results are obtained when bulk fermentation is practiced. In this method, the leaves are assorted into piles, depending on what part of the stalk they have been taken from. Layer after layer of leaves are placed together, until piles of more than 1 meter are reached. The temperature in the pile gradually rises, and frequently thermometers are inserted to determine the exact degree of heat, which is never allowed to become excessive, or the tobacco will be injured. The piles are frequently turned over, to secure the proper heat and regulate the fermentation. No statement can be made as to how often the piles should be turned over, or when this should be done, as it depends upon the condition of the 
tobacco, especially as to how moist it was when placed in the pile. The leaves from the upper part of the stalk must be fermented more slowly than the lower leaves; consequently, the piles must be torn down and rebuilt more often. The principal fermentation is one before the sorting as, after the sorting, there are so many grades which have to be kept separate. Often these different grades are refremented to improve the quality of the leaf.

In the Cagayan Valley the tobacco is placed into packs of four bundles of from 20 to 40 leares. These bundles are then placed into bales of 80 packs. From 1 hectare an average yield for a number of years is 612 kilos of dry leaves. The tobacco is frequently assorted with the following results: From 1 hectare, 10 packs of superior tobacco, 30 packs of first-class, 40 packs of second-class, 80 packs of third-class, 160 packs of fourth-class, and number of packs of fifth-class tobacco. The sorting is generally carried on with reference to the colors, absence or presence of spots, length and soundness of leaf. Many divisions and subdivisions are made, according to market demands and the intended use of the tobacco. After the work of sorting and grading has been completed, it is baled into compact bales, when it is ready for shipment.

\section{GROWING TOBACCO UNDER SHADE.}

The growing of crops under shade is not a new idea, but was practiced perhaps hundreds of years ago; but the cultivation of fields of tobacco under a light cloth shelter of some character is comparatively recent. The idea of using shade startea in the United States in Florida, where in the last few years tobacco cultivation has made enormous advances. It was noticed that in new land, only partially cleared of the forest growth, the plants grown under the scattered trees were far superior to plants not so shaded. From this the idea of artificial shade had its birth and now large fields, nearly 5 hectares in size, are grown under shade with great success.

In addition to the experiments in Florida, many trials have been made in the State of Connecticut, with equal success. The character and quality of the tobacco was considerably modified and profits greatly increased. It was determined that tobacco fully equal to the finest Sumatra leaf could be grown in the Connecticut Valley on a commercial scale, and the experiments received widespread attention, and large companies have been formed to grow tobacco exclusively under shade. By using the shade, the damage from insect pests is reduced to a minimum, the moisture content of the soils is increased, while the evaporation from the leaves is largely retained, favoring a more rapid and luxurious growth. The shelter tempers to some extent the intense heat of the sun and at the same time readily allows the free passage of even the slightest showers through it. 
In figure 2 is shown the general appearance of a tobacco field covered with a cheese cloth shelter. The field contains about $4 \frac{1}{2}$ lectares and is one of a number of large fields of shaded tobacco grown in Florida in 1899. In figure 3 is shown the details of the outside structure of the framework, before the covering was put on. In figure 4 is shown the details of the framework of a shade that was used in the Connecticut Valley in 1901. A strong framework is constructed of posts and stringers, that is further strengthened by strong wires secured at each end of the field by strong stakes driven well into

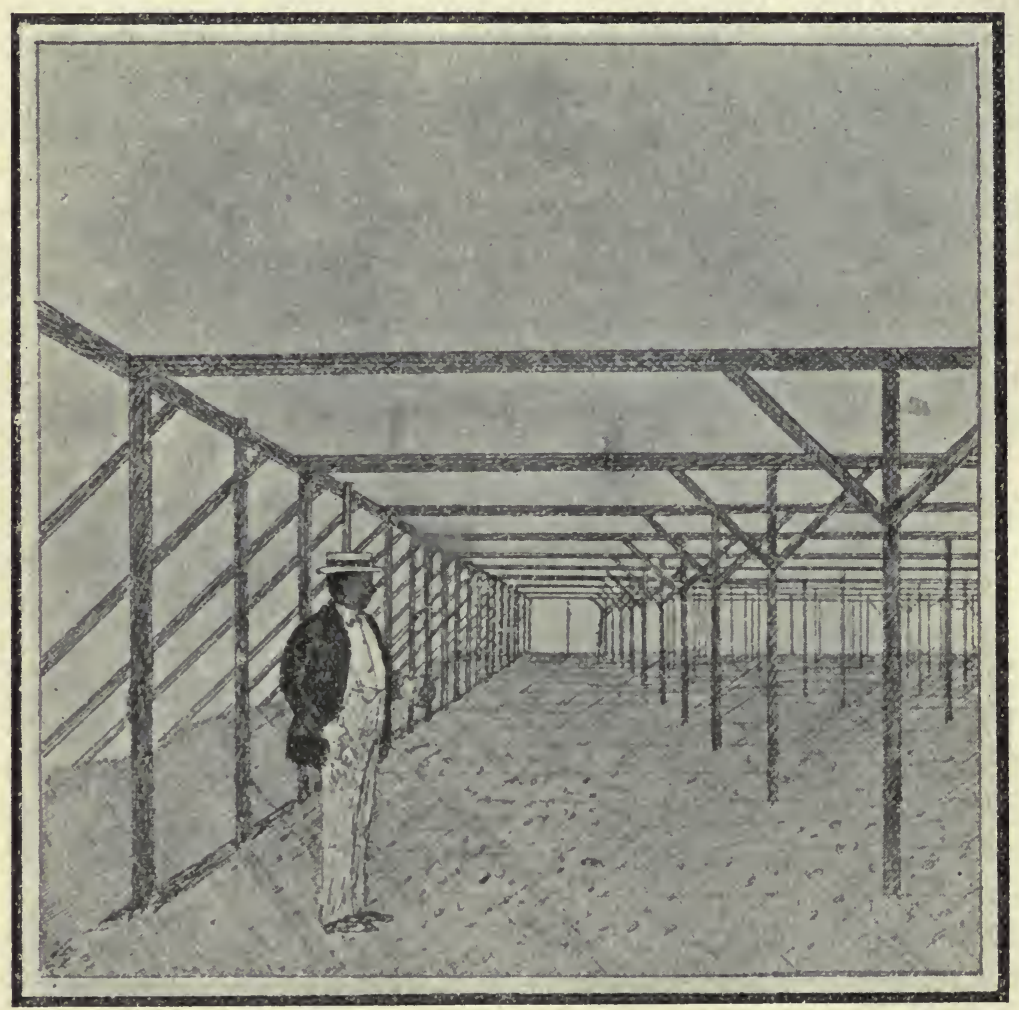

Fig. 4.-Framework used in Connecticut.

the ground. This is covered with some light cloth, such as cheese cloth. BY special request, an extra wide (about 5 meters) quality of cloth was made for the season of 1902. The cloth completely covers the framework and reaches to the ground, where it is secured. Gates are provided, covered with cloth, and, in the fields of large dimensions, it is advisable to leave a road lengthwise through the field. Usually, the cloth must be renewed each season, but the framework is built sufficiently strong to last four or five years. The height of the framework is about 3 meters and the average total cost of the shade in the United States is about $\$ 350$, 
United States currency, for 1 acre, 0.4 hectare. In the Philippines such a shelter could be constructed much more cheaply, on account of the cheapness of the framework, for bamboo and bejuco could be substituted largely for hard wood posts and wire.

The covering completely incloses the field, and should be made so close that few, if any, insects can enter. The protection from strong winds is very beneficial, as the leaves are often torn and lashed when the crop is not protected. Much protection is also afforded from heary, dashing rains, which would otherwise damage the leaves. The force of the heavy rainfall is broken and frequently the crop is saved when, without protection, it would be badly torn and damaged. So much better results have been accomplished in the United States with the shade-grown tolbacco that an earnest plea is made for its introduction into the tobacco districts in the Philippines. Rumors have stated that the attempt is to loe made in the Cagayan Valley, but the author can not state how far these experiments have been conducted, or what success has been attained. It will, of course, be advisable to experiment on a small scale, rather than expend any considerable amount of money on materials for shading large fields. A shade of sufficient size should be constructed to determine to what extent the crop will be benefited, and then plans can be made fur the erection of larger coverings.

\section{CONCLUSIONS.}

From the above, it is at once apparent that the successful cultivation of tobacco requires the greatest care and attention, from the preparation of the seed bed to the final fermentation and baling of the ripened leares. While anyone unfamiliar with tobacco culture can probably produce a crop, it is to be doubted if it will be of such a character as to command a good price. Judgment, only to be gained through experience in growing the crop, is necessary at so many stages of the growth of the plant that it is doubtful if it is profitable for the planter to undertake its cultivation unless he can engage the services of some one who has had such experience. And yet it is possible for the careful planter, who persistently studies the requirements of the crop, in a very few years to produce tobacco of a quality superior to that grown in regions where its cultivation has been practiced for scores of years. When the Department of Agriculture attempted growing Sumatra tobacco under shade in the Connecticut Valley, the idea was greatly ridiculed by conservative New England planters, who scoffed at the idea of trying to grow a new kind of tobacco. They maintained they had grown tobacco for years, and knew the limitations of the soils and climate and the kind of tobacco best suited to the conditions. It took only one year to convince them that a new type of tobacco could be grown and sold for prices many times in advance of the best prices ever obtained for the finest of the old standard 
crop. And this has been the experience of tobacco cultivation the world over. Experiments have been tried in tobacco growing in new areas and in a few years, in many cases, have entirely revolutionized the agriculture in certain districts. New areas are constantly being opened up, with results that are very gratifying, even to the most sanguine experimenters.

In the districts where tobacco cultivation has been carried on for years, no one should be contented with the results obtained, but should by constant experimentation with new seed and improved cultivation endeavor to improve the quality of the crop. Here in the Philippines it is commonly stated that the tobacco grown to-day is inferior to that formerly grown. This is greatly to be regretted, and it should be the especial effort of every planter to produce tobacco not equal to that grown a few years ago, but far superior to the finest crops that were ever harvested. The tobacco markets of the world willingly pay, and pay well, too, for tobacco of a superior quality, whether it is to be used for cigars, cigarettes or manufacturing purposes. The trade does not pay wcll for common tobacco, for anyone can grow coarse, common tobacco of low grade. The quality of the tobacco must be superior to that formerly grown to command a good price, for tobacco consumers are becoming more fastidious and constantly demand better goods for their money.

The author is of the opinion that the Philippine Islands can and should produce cigar-filler tobacco that is fully equal to the finest product of the famous Vuelta Abajo us trict of Cuba, and a cigar wrapper equal to Sumatra tobacco. With careful attention to soil and climatic conditions, it is believed districts can be found that will raise tobacco similar in flavor and aroma to that grown in the best districts of Turkey. These results can only be obtained, however, by persistent, intelligent, welldirected efforts on the part of the planter.

Philippine tobacco to-day does not occupy the position it should, and every planter or company engaged in its cultivation should strive to place it on the high standard it deserves. 



\section{RETURN CIRCULATION DEPARTMENT}

TO $\longrightarrow 202$ Main Library

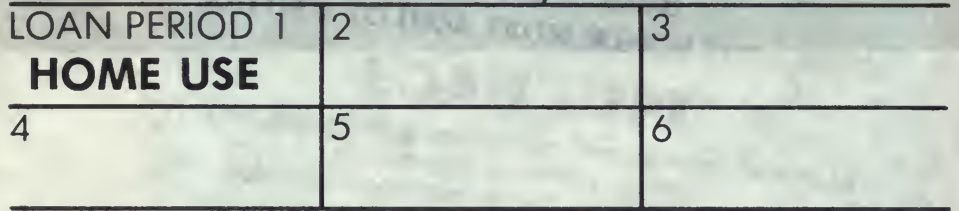

ALL BOOKS MAY BE RECALLED AFTER 7 DAYS

Renewals and Recharges may be made 4 days prior to the due date.

Books may be Renewed by calling $\quad 642-3405$

\section{DUE AS STAMPED BELOW}

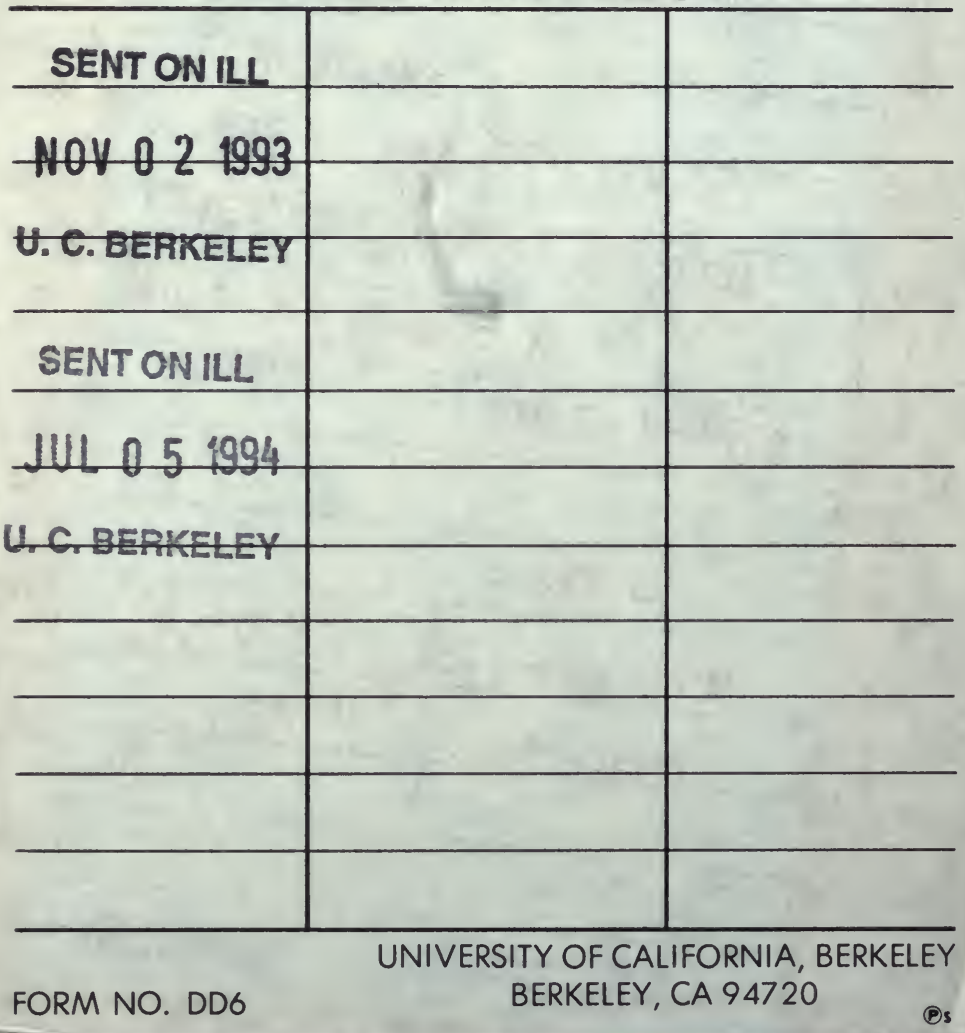


